\title{
Aspectos morfofisiológicos e bromatológicos de Paspalum plicatulum
}

\author{
Simone Meredith Scheffer-Basso ${ }^{1}$, Milena Maria Gallo ${ }^{2}$
}

\author{
1 Universidade de Passo Fundo. Bolsista CNPq. \\ 2 Curso de Ciências Biológicas, Universidade de Passo Fundo.
}

RESUMO - Este trabalho foi conduzido com o objetivo de avaliar o valor forrageiro de uma população de capimcoqueirinho (Paspalum plicatulum) por meio das características bromatológicas e do acúmulo de matéria seca. As plantas foram obtidas a partir de touceiras e transplantadas em área livre de invasoras distantes $80 \mathrm{~cm}$ entre si. O delineamento foi completamente casualizado e os tratamentos consistiram da idade das plantas após o estabelecimento, caracterizada pelos dias (D) e graus-dia (DD) acumulados acima de $0^{\circ} \mathrm{C}$. As colheitas foram feitas rente ao solo no final da primavera $(27 \mathrm{D}=587$ GD) e meados do verão (68 D, 1534 GD), outono (149 D, 3311 GD) e inverno (226 D, 4527 GD). O capim-coqueirinho apresentou 11 a 22\% de proteína bruta, 39 a 46\% de fibra em detergente ácido e 55 a 66\% de fibra em detergente neutro, boa tolerância a seca estival e produção de matéria seca verde durante a primavera-verão-outono. A produção foi interrompida quando as temperaturas reduziram para abaixo de $15^{\circ} \mathrm{C}$. Morfologicamente, a população de Paspalum plicatulum apresenta elevado potencial de afilhamento (105/planta), touceiras compactas (circunferência $=53 \mathrm{~cm}$ ), brotações basais e hábito cespitoso.

Palavras-chave: afilhamento, capim-coqueirinho, fibra em detergente ácido, fibra em detergente neutro, matéria seca, proteína bruta

\section{Morphophysiological and bromatological aspects of Paspalum plicatulum}

\begin{abstract}
This work aimed to evaluate the forage value of a brown-seed grass (Paspalum plicatulum) population, considering bromatological aspects and dry matter accumulation. Plants were obtained from tussocks and they were established in a weed-free area $80 \mathrm{~cm}$ apart from each other. The experimental design was completely randomized and treatments consisted of plant age after establishment characterized by days (D) and degree-days (DD) accumulated above $0^{\circ} \mathrm{C}$. Harvests were performed at ground level in late-spring (27 D, 587 DD), mid-summer (68 D, 1534 DD), mid-fall (149 D, 3311 DD), and mid-winter (226 D, 4527 DD). Brown-seed grass showed 11-22\% of crude protein, 39-46\% of acid detergent fiber and $55-66 \%$ of neutral detergent fiber, good tolerance to summer drought, and produced green dry matter during spring, summer and fall. Growth stopped when the temperatures dropped below $15^{\circ} \mathrm{C}$. Morphologically the population showed a high tillering potential (105/plant), compact tussocks (circumference $=53 \mathrm{~cm}$ ), basal sprouting, and erect growth.
\end{abstract}

Key Words: acid detergent fiber, brown-seed grass, crude protein, dry matter, neutral detergent fiber, tillering

\section{Introdução}

O gênero Paspalum é o mais importante das gramíneas estivais do Brasil e possui características morfológicas compatíveis com a utilização sob pastejo, além de composição química adequada à produção de ruminantes (Costa \& Scheffer-Basso, 2003; Baréa et al., 2007). Entre as espécies do gênero, destacam-se o capim-coqueirinho, o capim-felpudo ou o pasto-negro (Paspalum plicatulum Mitchx). É uma das principais espécies dos campos limpos da microrregião Campos da Mantiqueira (Evangelista et al., 1999), em Minas Gerais, e na sub-região dos Paiaguás, no Pantanal
(Almeida et al., 1996). No Sul do Brasil, juntamente com o capim-melador (Paspalum dilatatum Poir), essa espécie evidencia a importância do gênero, pois apresenta grande resistência ao pisoteio e a cortes freqüentes e, ainda, bom desenvolvimento em solos pouco férteis (Batista \& Godoy, 1998). Na Austrália, há registro dos cultivares Rodd’s Bay, Bryan e Hartley (AHPC, 1972). O cultivar Hartley é originado de sementes coletadas no Brasil em 1948, o que confirma a importância do germoplasma do País como fonte de materiais forrageiros para outros países. Na Venezuela, a espécie se destaca por seu valor nutritivo nas pastagens naturais das savanas da região de Cojedes (Espinoza et al., 2000). 
O capim-coqueirinho é classificado como tetraplóide apomítico, mas há referências de acessos diplóides sexuais (Pozzobon et al., 2000). É perene, cespitoso, e possui até $120 \mathrm{~cm}$ de altura. O pico do crescimento ocorre no verão; é lento no início da primavera e diminui a partir da floração. A temperatura mínima para seu crescimento é de 6 a $14^{\circ} \mathrm{C}$ e a ótima de 18,9 a $23,3^{\circ} \mathrm{C}$ (Skermann \& Riveros, 1992).

Populações dessa espécie, assim como de outras plantas forrageiras nativas, têm sido encontradas às margens de rodovias, na região Norte do Rio Grande do Sul, pois o avanço da agricultura sobre as áreas de pastagens naturais e florestas promoveu a fragmentação do Bioma Mata Atlântica. Por isso, estudos básicos sobre as características forrageiras em materiais ainda não utilizados comercialmente podem contribuir para a valorização e a conservação do germoplasma nativo.

Este trabalho foi conduzido com o objetivo de avaliar o valor forrageiro de uma população de $P$. plicatulum por meio de suas características bromatológicas e do acúmulo de matéria seca.

\section{Material e Métodos}

O trabalho foi conduzido em Passo Fundo, região fisiográfica do Planalto Médio do Rio Grande do Sul, com coordenadas geográficas de $28^{\circ} 15^{\prime} \mathrm{S}$ e $52^{\circ} 24^{\prime} \mathrm{W}$ e $687 \mathrm{~m}$ de altitude média. O clima pertence à Zona Climática Fundamental Temperada C, com clima fundamental úmido (f) e variedade subtropical (Cfa) (Moreno, 1961) (Figura 1). O solo do local do ensaio apresentou a seguinte composição:

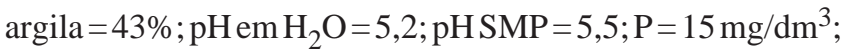
$\mathrm{K}=118 \mathrm{mg} / \mathrm{dm}^{3} ; \mathrm{MO}=2 \% ; \mathrm{Al}=1,1 \mathrm{cmolc} / \mathrm{dm}^{3}$.

O ensaio foi estabelecido em área de lavoura, previamente dessecada em 18/11/2004, mediante o transplante de 100 mudas com 3 a 4 afilhos, distantes $0,80 \mathrm{~m}$ entre si. As mudas foram formadas por meio da divisão de touceiras de uma população presente no km 171 da BR 285, em frente ao pórtico da Universidade de Passo Fundo, Campus I. Após o transplante, efetuou-se um corte de emparelhamento a 10 $\mathrm{cm}$ acima da base das plantas. As plantas foram irrigadas manualmente durante uma semana.

O delineamento foi completamente casualizado, com oito repetições (plantas individuais), considerando como tratamento a idade das plantas após o transplante. As plantas outliers, ou seja, aparentemente muito superiores ou muito inferiores à media, foram descartadas do sorteio, no qual foram demarcadas as idades das avaliações.

As colheitas foram feitas ao final da primavera (15/12/ 2004) e meados do verão (25/1/2005), outono (16/4/2005) e inverno (2/7/2005), correspondendo aos 27, 68, 149 dias e 226 dias de idade após o transplante. A altura e circunferência das touceiras foram avaliadas nestas datas e, também, em

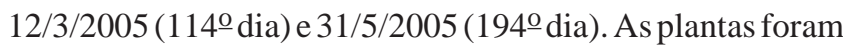
cortadas na base e separadas em material morto (MSMM) e material verde (MSMV), que foram secos em estufa a $60^{\circ} \mathrm{C}$ sob circulação de ar até peso constante. As amostras do material verde (folhas, caules e inflorescências) foram moídas e analisadas quanto aos teores de proteína bruta, fibra em detergente ácido e fibra em detergente neutro, pelo método de reflectância no infravermelho proximal (NIRS), cuja curva de calibração foi realizada no Centro de Pesquisa em Alimentos/UPF. Os dados foram submetidos à análise de regressão considerando a soma térmica (Romo \& Eddleman, 1995) e temperatura basal de $0^{\circ} \mathrm{C}$.

\section{Resultados e Discussão}

Nos quatro meses após o plantio das mudas, ocorreu uma estiagem severa na região, especialmente em fevereiro, quando a precipitação foi de apenas $26 \mathrm{~mm}$ (Figura 1). Apesar da estiagem, verificou-se total sobrevivência das plantas, evidenciando a boa tolerância da espécie à seca, conforme destacado por Carvalho \& Cruz Filho (1985). As plantas aumentaram em tamanho, tanto em altura quanto em circunferência (Figura 2), especialmente a partir da normalização da pluviosidade (Figura 1). A altura média foi de $91 \mathrm{~cm}$, similar à citada em AHPC... (1972), de 1,0 a 1,2 m.

A circunferência da touceira foi, em média, de $34 \mathrm{~cm}$ e atingiu o maior valor à época de maior afilhamento (Figura 3). Esse comportamento comprovou que o capimcoqueirinho, apesar de ser estival, apresenta potencial para crescimento no outono, uma característica importante, pois nessa época ocorre severa escassez de forragem no Sul do

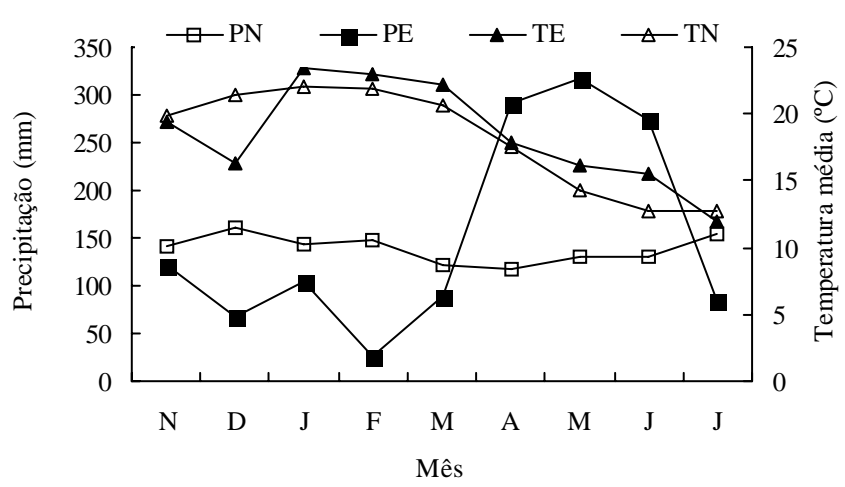

Figura 1 - Precipitação (PE) e temperatura média mensal (TE) durante o período experimental e normais regionais (PN, TN). Fonte: www.cnpt.embrapa.br. 

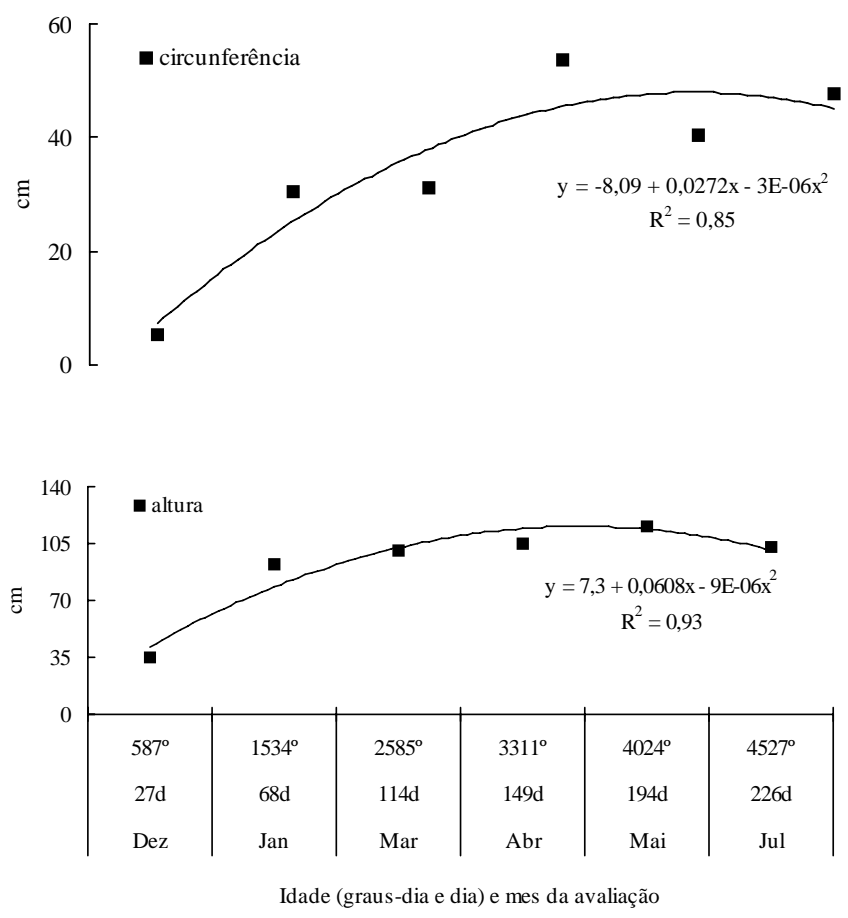

Figura 2 - Tamanho de plantas de uma população de $P$. plicatulum considerando a soma térmica (Temperatura basal = $\left.0^{\circ} \mathrm{C}\right)$.

Brasil. Os afilhos se originaram da base da planta, confirmando observações de Comastri Filho \& Pott (1982), que caracterizaram o capim-coqueirinho como portador de gemas de renovação do tipo basal. Esse caractere é uma das mais importantes características para garantir a persistência de forrageiras sob pastejo. Em capim-das-roças (P. urvillei Steudel), Scheffer-Basso et al. (2002) também verificaram que a origem dos afilhos é, na maioria, basilar.

Com a redução das temperaturas a partir de abril, o número de afilhos das plantas diminuiu, o que está de acordo com relatos de Skermann \& Riveros (1992) sobre as exigências térmicas da espécie, estipuladas em mínimas de 6 a $14^{\circ} \mathrm{C}$ e ótimas de 18,9 e $23,3^{\circ} \mathrm{C}$. O afilhamento aumentou até meados do outono, quando as plantas apresentaram aproximadamente 120 unidades de afilhos, dos quais $90 \%$ estavam em estádio vegetativo. O maior número de afilhos ocorreu aos 3.311 graus-dia, em abril. No mesmo local, Scheffer-Basso et al. (2002) verificaram que o pico de afilhamento (70 afilhos/planta) em capim-das-roças ocorreu aos 2.666 graus- $d i \mathrm{~T}_{\mathrm{Tb}=0^{\circ} \mathrm{C}}$ (janeiro), o que indica diferenças intragenéricas quanto ao potencial de afilhamento, à adaptação às temperaturas outonais e ao ciclo produtivo.

O pico do florescimento ocorreu aos 1534 graus-dia (68음 dia de crescimento) e os afilhos reprodutivos representaram aproximadamente $32 \%$ do total (Figura 3). Como as

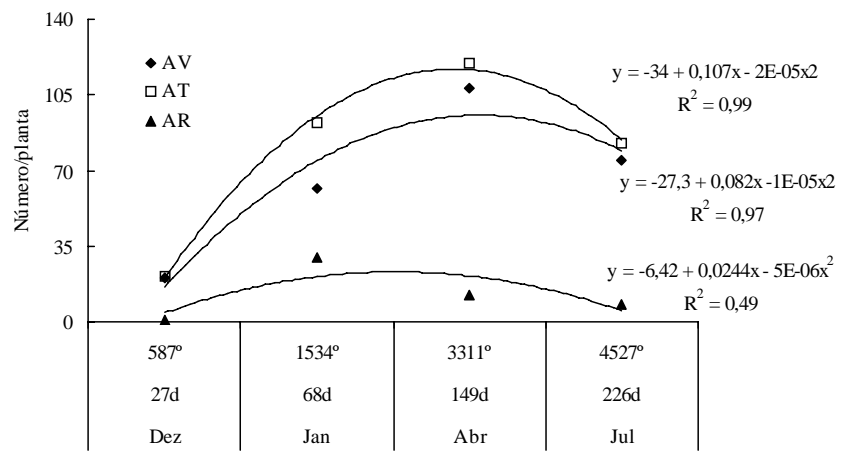

Idade (graus-dia e dias) e mes da colheita

Figura 3 - Afilhos reprodutivos (AR), vegetativos (AV) e totais (AT) de uma população de Paspalum plicatulum considerando a soma térmica (Temperatura basal = $\left.0^{\circ} \mathrm{C}\right)$.

mudas foram oriundas de plantas-mães em início de florescimento, não se pode afirmar que esse processo seja tão sincronizado na espécie e restrito a esse período. $\mathrm{Na}$ Austrália, no entanto, o cv. Hartley floresce por um curto período no final do verão (AHPC..., 1972). Em capim-dasroças, Scheffer-Basso et al. (2002) verificaram início de florescimento aos $878 \mathrm{GD}_{\mathrm{Tb}=0^{\circ} \mathrm{C}}$, que se manteve estável até o final do ciclo, aos 4.098 graus-dia. No capim-virasoro (P. dilatatum biótipo Virasoro), o florescimento também é longo e se inicia na primavera, prolongando até o final do verão, o que reduz consideravelmente o percentual de folhas (Costa \& Scheffer-Basso, 2003; Baréa et al., 2007). Considerando os critérios adotados por Almeida (1995) para a classificação de gramíneas em grupos fenológicos, provavelmente o capim-coqueirinho seja do grupo de ciclo curto (PCC), no qual constam as gramíneas com florescimento de 1 a 3 meses. Contudo, essa classificação precisa ser validada para as condições do Sul do Brasil, uma vez que foi realizada em condição de cerrado, no Distrito Federal, onde as situações ambientais mais contrastantes são atribuídas à pluviosidade e, no Sul, às temperaturas contrastantes.

A curva de produção de matéria seca verde foi similar à do afilhamento, mas a estiagem do verão reduziu a proporção desse material em relação à produção e alocação de material morto (Figura 4). Essa fração aumentou linearmente, em razão das condições pluviométricas no verão e da redução nas temperaturas a partir do outono. Além disso, como as plantas foram avaliadas destrutivamente e intactas, os colmos e as folhas senescentes se acumularam na touceira.

Em meados do inverno (julho), a produção de material morto representou $88 \%$ da parte aérea das plantas. Em cortes periódicos ou sob pastejo, essa situação seria 

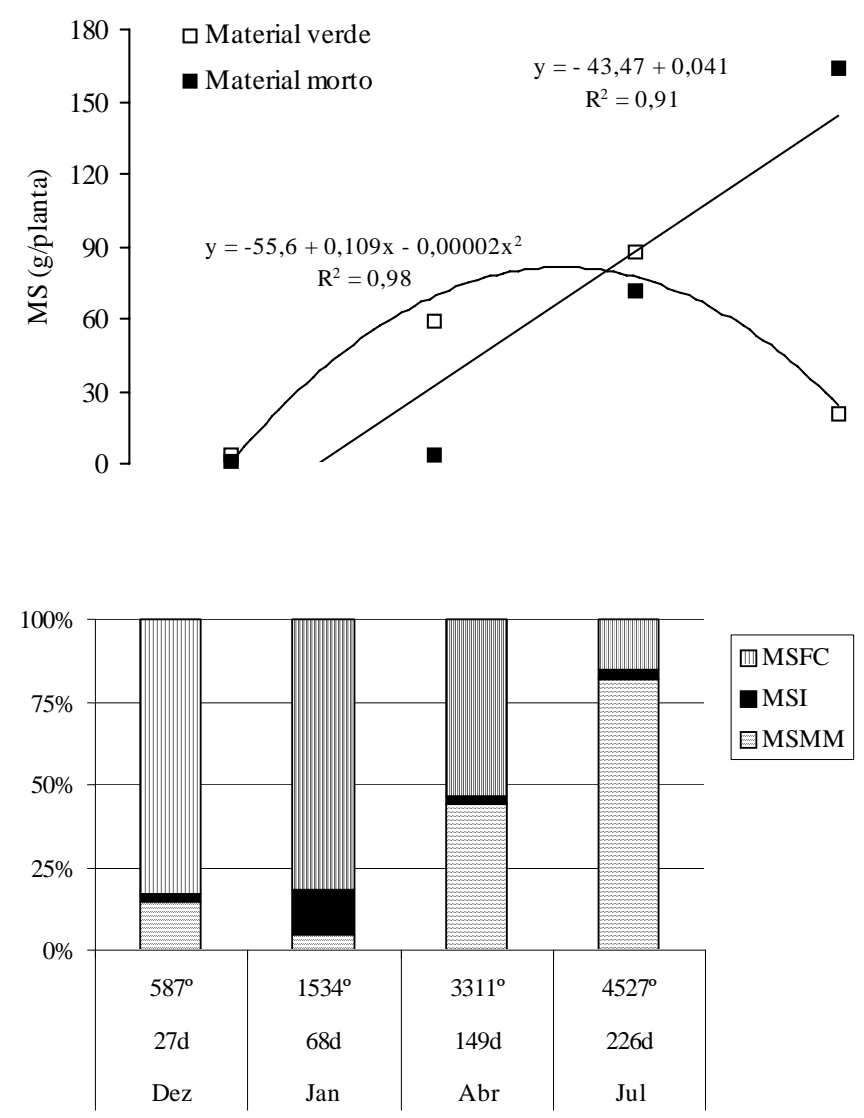

Figura 4 - Produção e alocação da matéria seca(MSFC = caule+folha, MSI = inflorescências, MSMM = material morto) de uma população de Paspalum plicatulum considerando a soma térmica (Temperatura basal $=0^{\circ} \mathrm{C}$ ).

diferente, em virtude da remoção do material morto, e possivelmente haveria efeito positivo sobre o afilhamento, em resposta às melhores condições de luminosidade na base da planta. O acúmulo de material morto ocorreu até meados do outono (abril), em razão do afilhamento, com o máximo estimado em 71,88 g MS/planta, aos $3311 \mathrm{GD}_{\mathrm{Tb}=0^{\circ} \mathrm{C}}$ (Figura 4). Esse comportamento indica que o capimcoqueirinho não interrompeu seu crescimento até a redução das temperaturas próximas a $15^{\circ} \mathrm{C}$, e posteriormente abaixo disso, o que está de acordo com indicações de Skerman \& Riveros (1992). Shaw et al. (1965) também observaram altas taxas de crescimento da espécie durante o verão-outono, na Austrália. No capim-das-roças, o maior acúmulo de matéria seca ocorreu, de forma similar, aos 2969 graus-dia $\mathrm{Tb}=0^{\circ} \mathrm{C}$, porém, em pleno verão (Scheffer-Basso et al., 2002).

As características relacionadas ao valor nutritivo tiveram maior alteração entre os 27 e 68 dias de idade e, a partir daí, tenderam à estabilização (Figura 5). Esse comportamento decorreu de seu crescimento mais lento durante as estações menos favoráveis (Shaw et al., 1965), ao contrário do que

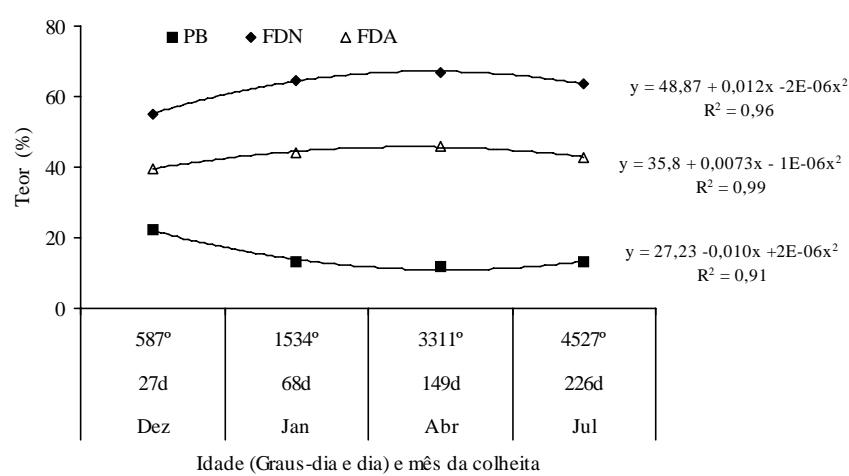

Figura 5 - Teor de PB, FDA e FDN de uma população de Paspalum plicatulum considerando a soma térmica (Temperatura basal $=0^{\circ} \mathrm{C}$ ).

ocorre em temperaturas mais altas. Além disso, as amostras analisadas foram compostas apenas do material verde. A inclusão do material morto certamente reduziria os teores de proteína bruta e elevaria as concentrações de fibra em detergente ácido (FDA) e fibra em detergente neutro (FDN). O componente nutritivo que teve maior variação foi proteína bruta, que teve redução de $46 \%$. Os teores de FDA e FDN aumentaram, na mesma época, 13,3 e 17\%, respectivamente. As concentrações de PB, FDA e FDN variaram, na média, de 11,7 a 22,3\%, 39,5 a 45,9\% e 55 a $66,8 \%$, respectivamente, e esta variação está relacionada ao processo ontogenético. Com o florescimento, ocorre alongamento dos entrenós, que resulta em maior contribuição dos colmos no material verde. A composição química do capim-coqueirinho foi similar à descrita por Costa et al. (2003) para o capim-virasoro (PB folhas $=19 \%, F D A=43 \%$, FDN $=73,9 \%$ ), espécie reconhecida por seu elevado valor forrageiro. Shaw et al. (1965) obtiveram teor máximo de proteína bruta de 14\% no capim-coqueirinho, na Austrália. Em comparação a espécies já melhoradas e utilizadas comercialmente, a espécie não deixa a desejar. Rocha et al. (2001) quantificaram em Cynodon spp. concentrações médias de 72,1 a 75,1\% de FDN e 39,5 a 40,7\% de FDA.

\section{Conclusões}

A espécie Paspalum plicatulum apresenta características bromatológicas compatíveis com as exigências mínimas para produção de ruminantes, tem boa tolerância à seca e mantém a produção de matéria seca verde durante o outono. Além disso, possui elevado afilhamento e forma touceiras compactas a partir de brotações basais, em hábito tipicamente cespitoso. 


\section{Literatura Citada}

AHPC - REGISTER OF AUSTRALIAN HERBAGE PLANT CULTIVARS. [1972]. Disponível em: <http://www.pi.csiro.aus/ ahpc/grasses.> Acesso em: 3/11/07.

ALMEIDA, I.L.; ABREU, U.G.P.; LOUREIRO, J.M.F. et al. Introdução de tecnologias na criação de bovinos de corte no Pantanal - Sub-região dos Paiaguás. Corumbá: EMBRAPA-CPAP, 1996. 50p. (Circular Técnica, 22).

ALMEIDA, S.P. Grupos fenológicos da comunidade de gramíneas perenes de um campo cerrado no Distrito Federal. Pesquisa Agropecuária Brasileira, v.30, n.8, p.1067-1073, 1995.

BARÉA, K.; SCHEFFER-BASSO, S.M.; DALL'AGNOL, M. et al. Manejo de Paspalum dilatatum Poir. biótipo Virasoro. 1. Produção, composição química e persistência. Revista Brasileira de Zootecnia, v.36, p.992-999, 2007.

BATISTA, L.A.R.; GODOY, R. Capacidade de produção de sementes em acessos do gênero Paspalum. Revista Brasileira de Zootecnia, v.27, n.5, p.841-847, 1998.

CARVALHO, M.M.; CRUZ FILHO, A.B. Estabelecimento de pastagem. Coronel Pacheco: EMBRAPA-CNPGL, 1985. 46p. (Circular Técnica, 26).

COMASTRI FILHO, J.A.; POTT, A. Metodologia para avaliação de forrageiras. Corumbá: EMBRAPA-UEPAE, 1982. 27p. (Documentos, 2).

COSTA, D.I.; SCHEFFER-BASSO, S.M. Caracterização morfofisiológica e agronômica de Paspalum dilatatum Poir. biótipo Virasoro e Festuca arundinacea Schreb. 1. Desenvolvi-mento morfológico. Revista Brasileira de Zootecnia, v.32, n.5, p.1054-1060, 2003.

COSTA, D.I.; SCHEFFER-BASSO, S.M.; FÁVERO, D. et al. Caracterização morfofisiológica e agronômica de Paspalum dilatatum Poir. biótipo Virasoro e Festuca arundinacea Schreb. 2. Disponibilidade de forragem e valor nutritivo. Revista Brasileira de Zootecnia, v.32, n.5, p.1061-1067, 2003.

ESPINOZA, F.; DIAZ, Y.; VALLE, A. et al. Utilización del banco de energía como estrategia de manejo en sabanas del Estado Cojedes. I. Composición botánica. Zootecnia Tropical, v.18, n.2, p.197-212, 2000.

EVANGELISTA, A.R.; LIMA, J.A.; CURI, N. et al. Produção de matéria seca de pastagens nativas em áreas de Cambissolo e Latossolo. Ciência e Agrotécnica, v.23, n.4, p.987-992, 1999.

MOREnO, J.A. Clima do Rio Grande do Sul. Porto Alegre: Secretaria da Agricultura, 1961. 41p.

POZZOBON, M.T.; VALLS, J.F.M.; SANTOS, S. Contagens cromossômicas em espécies brasileiras de Paspalum L. (Gramineae). Acta Botânica Brasileira, v.14, n.2, p.151$162,2000$.

ROCHA, G.P.; EVANGELISTA, A.R.; PAIVA, P.C. Digestibilidade e fração fibrosa de três gramíneas do gênero Cynodon. Ciência Agrotécnica, v.25, n.2, p.396-407, 2001.

ROMO, J.T.; EDDLEMAN, L.E. Use of degree-days in temperature experiments. Journal of Range Management, v.48, n.5, p.410-416, 1995.

SCHEFFER-BASSO, S.M.; RODRIGUES, G.L.; BORDIGNON, M.V. Caracterização morfofisiológica e anatômica de Paspalum urvillei (Steudel). Revista Brasileira de Zootecnia, v.31, n.4, p.1674-1679, 2002.

SHAW, N.H.; ELICH, T.W.; HAYDOCK, K.P. et al. A comparison of seventeen introductions of Paspalum species and naturalized $P$. dilatatum under cutting at Samford, south-eastern Queensland. Australian Journal of Experimental Agriculture and Animal Husbandry, v.5, p.423-432, 1965.

SKERMAN, P.J.; RIVEROS, F. Gramínea tropicales. Roma: FAO, 1992. 849p. 